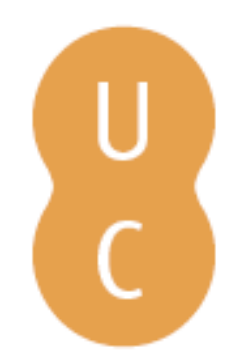

\title{
nommalina
}

\section{Análise empírica da fragilidade ambiental da bacia do rio Verde: Paraná, Brasil}

Autor(es): $\quad$ Passos, E.; Muratori, M.; Caneparo, S. C.

Publicado por: Imprensa da Universidade de Coimbra

URL

persistente: URI:http://hdl.handle.net/10316.2/31432

DOI: $\quad$ DOI:http://dx.doi.org/10.14195/978-989-26-0531-9_11

Accessed : $\quad$ 26-Apr-2023 03:19:36

A navegação consulta e descarregamento dos títulos inseridos nas Bibliotecas Digitais UC Digitalis, UC Pombalina e UC Impactum, pressupõem a aceitação plena e sem reservas dos Termos e Condições de Uso destas Bibliotecas Digitais, disponíveis em https://digitalis.uc.pt/pt-pt/termos.

Conforme exposto nos referidos Termos e Condições de Uso, o descarregamento de títulos de acesso restrito requer uma licença válida de autorização devendo o utilizador aceder ao(s) documento(s) a partir de um endereço de IP da instituição detentora da supramencionada licença.

Ao utilizador é apenas permitido o descarregamento para uso pessoal, pelo que o emprego do(s) título(s) descarregado(s) para outro fim, designadamente comercial, carece de autorização do respetivo autor ou editor da obra.

Na medida em que todas as obras da UC Digitalis se encontram protegidas pelo Código do Direito de Autor e Direitos Conexos e demais legislação aplicável, toda a cópia, parcial ou total, deste documento, nos casos em que é legalmente admitida, deverá conter ou fazer-se acompanhar por este aviso. 



\title{
ANÁLISE EMPÍRICA DA FRAGILIDADE AMBIENTAL DA BACIA DO RIO VERDE - PARANÁ, BRASIL
}

\author{
EMPIRICAL ANALYSIS OF ENVIRONMENTAL FRAGILITY OF \\ THE RIO VERDE BASIN - PARANA, BRAZIL
}

E. Passos ${ }^{1}$, M. Muratori ${ }^{1} \&$ S. C. Caneparo ${ }^{1}$

\begin{abstract}
Resumo - A Bacia do Rio Verde, área-objeto do presente estudo, localizada na Região Metropolitana de Curitiba, Paraná - Brasil, tem, dentre seus diversos usos, o fornecimento de água para a Refinaria Presidente Getúlio Vargas - REPAR, pertencente à petrolífera Petrobras. Tendo em vista as formas de ocupaçáo desordenada dessa bacia ao longo dos anos, existe uma série de desequilíbrios ambientais, os quais podem deteriorar na sequência, a qualidade de suas águas. Nesse contexto, procurou-se avaliar as características físico-ambientais da bacia quanto a sua capacidade de suporte, identificando-se os níveis de fragilidade potencial e emergente, resultante da atuação de processos geológico-geomorfológicos, integrando os aspectos litológicos e tectono-estruturais em interação com as características climáticas pretéritas e atuais, o relevo, os solos e a vegetação, frente à ação humana. Para essa análise, foi adotada a metodologia que tem como base os critérios estabelecidos por TRICART (1977) relacionados às unidades ecodinâmicas, classificando os meios em estáveis, intergrades e fortemente instáveis. Os resultados obtidos serviram como subsídio ao estabelecimento da fragilidade potencial e emergente da bacia, a serem utilizadas no planeamento e gestâo, de forma sustentável.
\end{abstract}

Palavras-chave - Bacia hidrográfica; fragilidade potencial; fragilidade emergente

Abstract - The Rio Verde Basin, the area object of the present study, located in the Metropolitan Region of Curitiba, Paraná - Brazil, has, among its many uses, the water supply to the Refinery Presidente Getuilio Vargas - REPAR, owned by the oil company Petrobras. Given the forms of sprawl in this basin over the years, there is a series of environmental imbalances, which can deteriorate the quality of its waters. In this context, it was sought to

${ }^{1}$ Universidade Federal do Paraná; passosever@gmail.com; amuratori@uol.com.br; sony@ufpr.br 
evaluate the physical and environmental characteristics of the basin, identifying the levels of potential and eminent fragility resulting from the geological and geomorphological processes, integrating aspects of tectono-lithological and structural interaction with the past and present characteristics, such as climatic, topography, soils and vegetation and human action. For this analysis, the methodology established by Tricart (1977) was adopted, related to ecodynamic units, classifying as stable, inter grades and strongly unstable. The results served as input to the establishment of eminent and potential fragility of the basin to be used in planning and management in a sustainable manner.

Keywords - Basin area; potential fragility, eminent weakness.

\section{1 - Introduçáo}

As políticas de planejamento no Brasil ainda são incipientes, dada uma série de fatores, quais sejam: a imensidáo do território e suas formas de ocupação.

As aglomeraçōes urbanas, historicamente concentradas nas porçôes próximas ao litoral, vêm determinando uma ocupação desordenada com efeitos negativos, tanto para as áreas urbanas como as periurbanas e mesmo rurais. Os ecossistemas são alterados devido ao desflorestamento, à perda de camadas superficiais de solos por processos erosivos acelerados, ao desaparecimento de nascentes, além de alteraçôes biofísicas e químicas das redes fluviais.

Esse é o caso da área-objeto do presente estudo, a bacia do rio Verde, localizada na porção oeste da Região Metropolitana de Curitiba, no estado do Paraná que, atualmente, desempenha um papel de suma importância, tendo em vista que suas águas, parcialmente barradas num reservatório, têm como um dos destinos abastecer a Refinaria Presidente Getúlio Vargas (REPAR), da Petrobras, que constitui o maior complexo industrial do sul do Brasil. Seu uso inclui água bruta para reposição do sistema de água de resfriamento circulante da refinaria; água para uso industrial e água para produção de vapor, dentre outros usos.

Embora os problemas de degradação ambiental estejam presentes em toda a bacia, há que salientar os referentes às áreas urbanas, cuja infraestrutura, na maior parte das vezes, é precária, além da ausência de práticas de manejo sustentável nas áreas rurais e de um descontrole quanto ao uso de agrotóxicos e fertilizantes.

Nesse contexto, coube aos autores do presente artigo, fazer um estudo integrado dessa bacia, utilizando ferramentas de sensoriamento remoto, aliadas ao Sistema de Informação Geográfica (SIG), buscando diagnosticar a fragilidade potencial e emergente, com o objetivo de avaliar suas características físico-ambientais, frente à capacidade de suporte, de maneira a subsidiar a gestão de uso da terra.

\section{2 - Contexto geoambiental da bacia do Rio Verde}

A bacia drenada pelo rio Verde, constitui um subsistema hidrográfico do rio Iguaçu, localizado na porçâo oeste da Regiáo Metropolitana de Curitiba, entre as latitudes de $25^{\circ} 18^{\prime} 5$ S e $25^{\circ} 40^{\prime} \mathrm{S}$ e longitudes de $49^{\circ} 21^{\prime} \mathrm{W}$ e $49^{\circ} 49^{\prime}$ W de Greenwich, ocupando uma 
área de 238,96 km², que abrange parte dos municípios de Campo Magro, Campo Largo, Balsa Nova e Araucária (Fig. 1 e Fig. 2).

É formada por sub-bacias, limitadas por colinas ou outeiros, em geral de topos remanescentes de antigas superfícies de aplainamento, convexizadas nas áreas menos dissecadas e mais mamelonizadas em porçóes de relevo mais acidentado, com interflúvios mais estreitos e condicionados à geologia, determinada pelos alinhamentos estruturais ou intrusóes, que no seu conjunto, definem um sistema com direçôes preferenciais NE-SO e NO-SE.

A drenagem principal dessas sub-bacias tem sua origem próxima aos topos, em pequenos anfiteatros de erosão (grotóes, hollows ou cabeceiras de drenagem) de onde convergem canais de primeira ordem (registrados em restituiçóes planialtimétricas 1:10.000), formando riachos ou córregos. Nos períodos de relativa estiagem, os pequenos cursos d'água de cabeceira, que têm suas nascentes em "olhos d'água ou fontes d'água" e que no sistema de drenagem constituem a protorrede de drenagem, secam ou diminuem consideravelmente seu volume e, desse modo, afetam a vazáo do coletor principal (riacho ou córrego) que define a microbacia hidrográfica componente da sub-bacia.

Do ponto de vista litoestrutural e tectônico a bacia do rio Verde assenta-se sobre a Unidade Morfoestrutural Cinturão Orogênico do Atlântico (ROSS, 1987), constituida por quatro grandes compartimentos geológicos, compreendendo as rochas metamórficas do Complexo Atuba, do Paleoproterozóico (BIGARELLA \& SALAMUNI, 1959), e do Grupo Açungui, do Neoproterozóico (MAACK, 1947) e sobre a Bacia Sedimentar de Curitiba, constituida por sedimentos das formaçóes Guabirotuba, do Eomioceno (BIGARELLA \& SALAMUNI, 1959; SALAMUNI, 1998) e Tinguis (BECKER, 1982) do Plio-Pleistoceno, além de depósitos aluvionares holocénicos. Essas unidades são seccionadas por rochas básicas e intermediárias de idade Jurocretácea, imprimindo uma direção preferencial de NW-SE

Quanto à morfologia, a área está referida à unidade morfoescultural do Primeiro Planalto Paranaense (MAACK, 1968), na qual os sistemas de relevo mais acidentados referem-se à Morraria do Açungui, correspondendo à porção setentrional, nas cabeceiras do rio Verde, e os mais aplanados à Bacia Sedimentar de Curitiba, na porção centro-meridional da bacia, no Planalto de Curitiba (CANALI \& MURATORI, 1981), até alcançar seu nível de base no rio Iguaçu, em presença de amplas planícies. É importante salientar que naquela porção setentrional “...ocorrem feiçóes de uma climatogénese antiga, em que quartzitos preservam formas de antigos inselbergs, testemunhos de um processo de pedimentação subatual.” (MURATORI \& PASSOS, 2011, p. 131). 

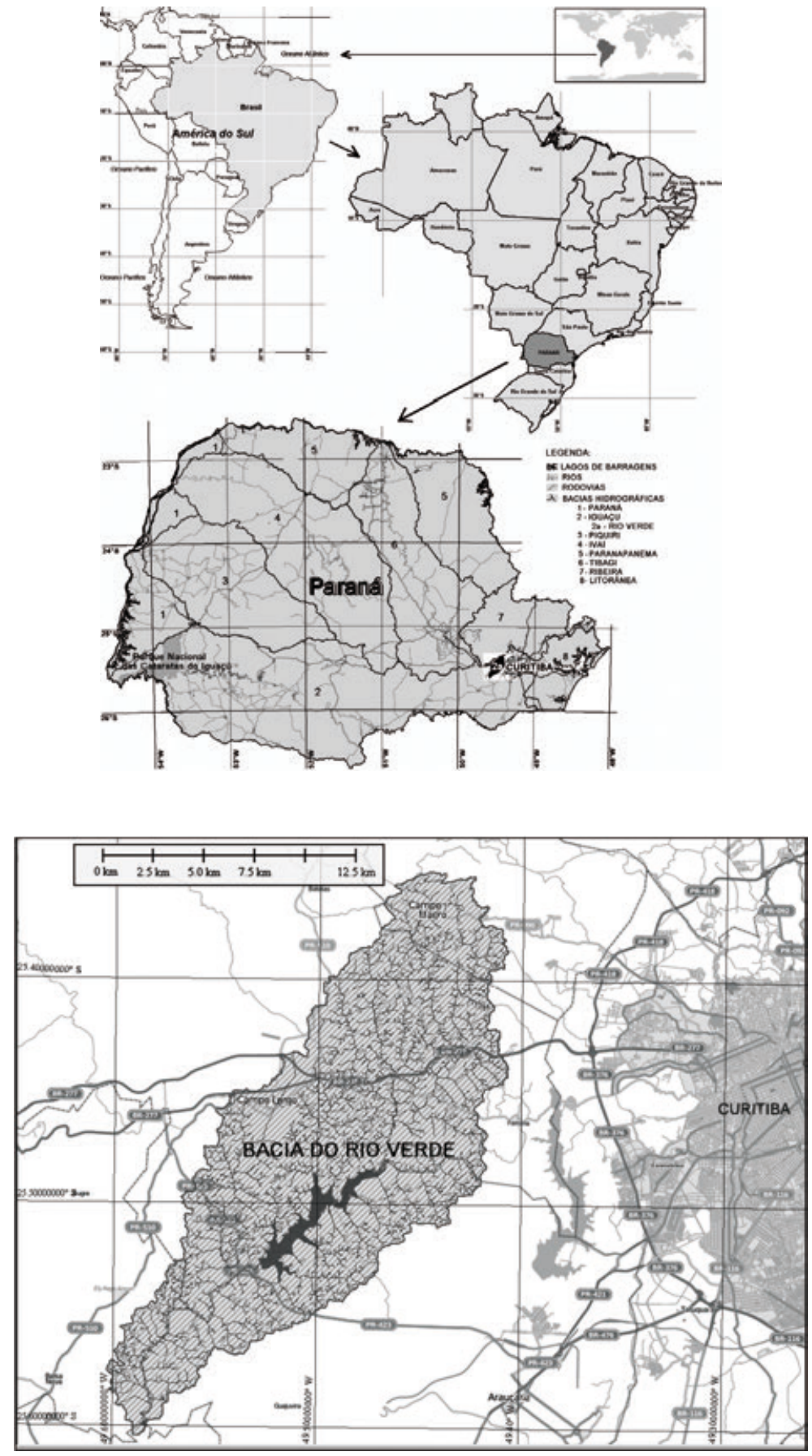

Fig. 1 e Fig. 2 - Localizaçấo: Área de estudo com detalhamento da rede hidrográfica e malha viária. (Coordenadas geográficas datum: WGS 84). 
De acordo com estudos efetuados por PASSOS (1987), a evolução dessas unidades geomorfológicas se prende a variaçôes de processos morfogenéticos e pedológicos, os quais determinaram modificaçóes do ponto de vista de sua estabilidade físico-química, cujos registros se fazem presentes na morfologia dos terrenos, o que permite uma análise temporo-espacial dos mesmos, fator essencial, em termos de planejamento ambiental.

O clima atual da área da bacia apresenta características subtropicais, classificando-se como Cfb, segundo KÖPPEN \& GEIGER (1928). A média anual de temperatura gira em torno dos $16,5^{\circ} \mathrm{C}$, com veróes frescos (média de $20,3^{\circ} \mathrm{C}$ ) e invernos frios (média de $12,7^{\circ} \mathrm{C}$ ), sendo que as chuvas estáo distribuídas ao longo do ano, sendo mais acentuadas nos meses de verão, totalizando valores anuais em torno de $1450 \mathrm{~mm}$.

O conjunto de tais características geológicas, morfológicas e climáticas determinaram as diferentes feiçóes dos solos e da cobertura vegetal, além do comportamento hídrico.

As áreas mais acidentadas correspondem a solos mais rasos com vegetação estépica e as áreas pediplanadas, a solos mais desenvolvidos. De acordo com KLEIN \& HATSCHBACH (1962), estão presentes, também, campos edáficos entremeados de capóes, constituídos pela Floresta Ombrófila Mista Montana em diversos estágios sucessionais.

O sistema de drenagem é diversificado, apresentando um padrão sub-paralelo, com vales em "v", tendendo a um padrão sub-dendrítico a dendrítico, em áreas de vertentes amplas. Com solos mais desenvolvidos, latossolos e argissolos, em associação com cambissolos, onde ocorrem colúvios por vezes truncados por linhas de seixos. Em áreas mais dissecadas, em presença de vertentes curtas, os cambissolos estão associados aos argissolos. Em fundos de vale predominam os gleissolos e organossolos.

\subsection{O fator humano e a modificação do meio ambiente}

De acordo com MURATORI \& PASSOS (2011), a rápida expansão de núcleos urbanos que ocorreu ao longo do tempo na área-objeto de estudo, somada às atividades industriais, agropecuárias, florestais e de mineração. Destacam-se no caso, os municípios de Araucária e Campo Largo, onde as atividades industriais instaladas, determinaram a expansão urbana, que ocorreu sem planejamento algum, seguida de processos degradacionais. Entretanto, é importante frisar que tais processos tiveram início anteriormente, com atividades primárias extensivas, com práticas agrícolas inadequadas, com desmatamento e ocupação de áreas que, obrigatoriamente, deveriam ser preservadas.

\section{3 - Pressupostos teórico-metodológicos}

Tendo como objetivo identificar a fragilidade potencial e emergente da Bacia Hidrográfica do Rio Verde - PR, optou-se pela abordagem sistémica, utilizando-se a proposição do geógrafo JEAN TRICART (1977), tendo em vista que ela constitui a base de estudos ambientais institucionais, no Brasil, tais como o Zoneamento Ecológico-Econômico (ZEE). Sua proposta tem como base a interação de matéria e fluxos de energia que estruturam os ecossistemas e que dirigem sua dinâmica e a sua sensibilidade às mudanças, considerando três grandes meios geodinâmicos para ordenamento e estabelecendo uma classificação, como se segue: 
Meios Estáveis - apresentam uma lenta evolução e estão afetos às regiōes de pouca atividade geodinâmica interna e onde os processos mecânicos de atividade externa também são pouco importantes, predominando processos pedogenéticos;

Meios intergrades (intermediários) - a dinâmica se caracteriza por uma interdependência morfogênese/pedogênese. Se a morfogênese predominar o meio se torna instável, mas se, ao contrário, os processos pedogenéticos predominarem, o meio tende para uma estabilidade;

Meios Instáveis - predomínio da morfogênese sobre a pedogênese. As causas podem ser consequentes de condiçóes bioclimáticas agressivas que desfavorecem a presença de cobertura vegetal e (ou) uma geodinâmica interna muito intensa e, na atualidade pela ação humana nos distintos ambientes.

Considerando esses aspectos MURATORI \& PASSOS, (2011), recorreu-se ao conjunto de dados no sentido de entender a dinâmica do meio natural e destacar as zonas ou fatores que podem limitar determinados usos do território, sendo útil para a ordenação dos recursos hídricos. Para tanto, recorreu-se à cartografia dos elementos naturais (litologia, relevo, cobertura vegetal, hidrografia, ações humanas), sua identificação, localização e análise dos diferentes processos e sistemas em interação dinâmica, compreendendo: coleta e análise de bibliografia e documentos cartográficos; preparação dos trabalhos de campo, com interpretação visual de fotografias aéreas e de imagens, visando a construção de um SIG; trabalhos de campo para checagem dos dados obtidos em gabinete e/ou laboratório; confecção dos mapas a partir de cartas topográficas e mapas temáticos; tratamento dos dados obtidos; interpretação; montagem do SIG, plotagem de mapas e elaboração do texto final.

\section{Essa proposição metodológica envolveu três grandes níveis de tratamento:}

a) Compartimentação do relevo com base na carta topográfica, com descrição precisa das formas de relevo, de acordo com AB'SABER (1969);

b) Extração de informaçóes sistemáticas da estrutura superficial da paisagem, a qual segue o modelo de mapeamento integrado apresentado por BIGARELLA et al. (1979) que, na adequação à cartografia digital, considera aspectos qualitativos e quantitativos do relevo, transformados em planos de informação (PIs) para compor o tema relevo no sentido amplo;

c) Análise da fisiologia da paisagem mediante o entendimento dos processos morfogenéticos e pedogenéticos, neste caso, integrado ao conceito de ecossistema, adaptado a uma perspectiva que define como resultantes dos referidos processos as unidades ecodinâmicas sistemáticas sugeridas por TRICART (1977) com a indicação da fragilidade de solo em função de instabilidade potencial e emergente.

\section{4 - Discussão dos resultados}

Considerando os pressupostos de TRICART (1977), a área da Bacia do Rio Verde foi compartimentada em unidades geodinâmicas, determinantes dos meios estáveis, intergrades e instáveis, as quais foram cartografadas, em unidades espaciais e organizadas em categorias de fragilidade potencial e emergente. 


\subsection{Fragilidade potencial da bacia do Rio Verde, RMC}

As categorias de fragilidade potencial (Fig. 3), variam desde insignificante, muito baixa, baixa, e moderada. De acordo com os dados obtidos, constatou-se que, sob a ótica geoambiental, a quase totalidade da bacia faz parte da unidade geodinâmica intergrade ou intermediária. Analisando cada categoria isoladamente, tem-se:

Insignificante (6\%): independe da litologia, tendo em vista apresentar, de maneira geral, uma cobertura pedológica espessa (Latossolos) sob a cobertura florestal (Floresta Ombrófila Mista), em declividades inferiores a 3\% situada em superfícies elevadas.

Muito Baixa (65\%): independe da litologia, tendo em vista contar, de maneira geral, como uma cobertura pedológica espessa referente a Latossolos e Argissolos, sob cobertura florestal (Floresta Ombrófila Mista) e estépica (campos), em declividades entre 3\% a $12 \%$, distribuídas em topos médios e estreitos e ao longo das vertentes.

Baixa (14,4\%): litologia referida às rochas do Grupo Açungui Floresta Ombrófila Mista sob manchas de estepe, em declividades de 12 a 30\% distribuídas em topos médios e estreitos e ao longo das vertentes. É importante citar que associadas a esta categoria ocorrem inclusóes de áreas pouco significativas para a escala de estudo, com vertentes bastante inclinadas, com declives acima de $30 \%$.

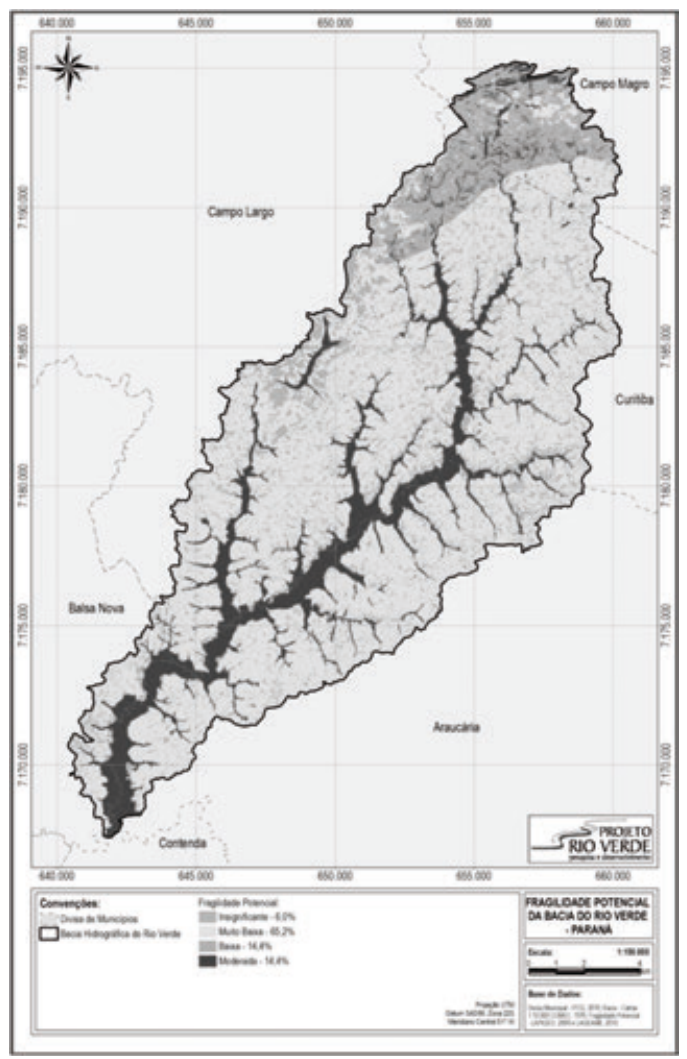

Fig. 3: Mapa de Fragilidade Potencial 
Moderada (14,4\%): Litologia referida a aluvióes sob Floresta Ombrófila Mista Aluvial e ocorrências de manchas de depósitos orgânicos sob estepe, e solos hidromórficos em declividades inferiores a $3 \%$.

Sintetizando, pode-se concluir que, quanto à fragilidade potencial, os componentes naturais da Bacia do Rio Verde determinam um estágio intermediário entre processos morfogenéticos e pedogenéticos, ou seja, uma interdependência entre a questão estabilidade/instabilidade do meio.

\subsection{Fragilidade emergente da bacia do Rio Verde, RMC.}

Para a obtenção do Mapa de Fragilidade Emergente da Bacia do Rio Verde (Fig. 4), cruzaram-se os planos de informação (PI's) das unidades geodinâmicas estabelecidas e representadas no Mapa de Fragilidade Potencial com os planos de informação referentes aos fatores de natureza antrópica.

As categorias de fragilidade emergente, obtidas pelos cruzamentos dos planos de informação (PIs) do meio natural e de natureza antrópica, variam desde insignificante, muito baixa, baixa, baixa a moderada, moderada, moderada a alta, alta e muito alta. De acordo com os dados obtidos, constatou-se que sob o prisma geoambiental, a quase totalidade da bacia (86\%) faz parte da unidade geodinâmica intergrade ou intermediária. Analisando cada categoria isoladamente, tem-se:

Insignificante (0,3\%): Áreas preservadas com cobertura florestal (Floresta Ombrófila Mista), independente da litologia, tendo em vista terem, de maneira geral, uma cobertura pedológica espessa (Latossolos) em declividades inferiores a 3\%, situadas em superfícies elevadas.

Muito Baixa (21,6 \%): Áreas conservadas com cobertura florestal secundária em estágio avançado da Floresta Ombrófila Mista e manchas de campo (estepe) em declividades entre $3 \%$ a $12 \%$, distribuídas em topos médios a estreitos e ao longo das vertentes.

Baixa a Moderada (1,2\%): Encontram-se associadas à litologia referida às rochas do Grupo Açungui sob Floresta Ombrófila Mista manchas de estepe, com declividades de 12 a 30\%, distribuídas em topos médios e estreitos e ao longo das vertentes. 


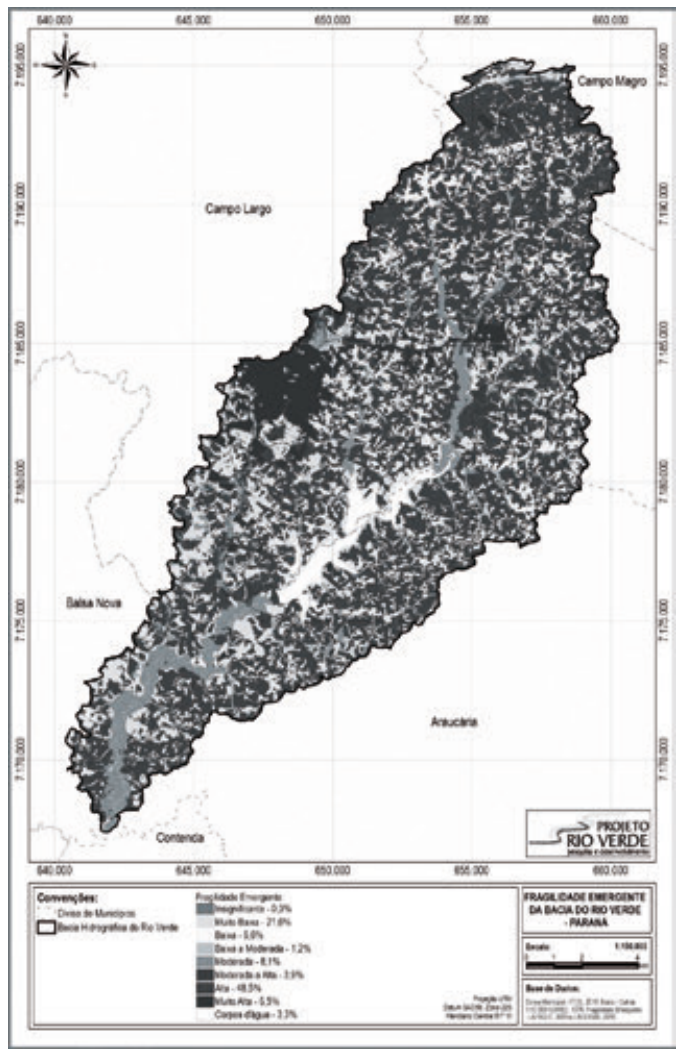

Fig.04: Mapa de Fragilidade Potencial

Associados a esta categoria ocorrem inclusóes de áreas pouco significativas que de acordo com a escala não são mapeáveis com declives acima de $30 \%$ relacionadas às categorias de Moderada a Alta, em presença de rochas carbonatadas e a filitos.

Moderada (8,1 \%): Litologia referida a aluvióes sob Floresta Ombrófila Mista Aluvial e ocorrências de manchas de depósitos orgânicos sob estepe, e solos hidromórficos em declividades inferiores a $3 \%$.

Moderada a Alta (3,9\%): Essa categoria independe da litologia, relaciona-se a áreas alteradas pela ação antrópica, onde as técnicas de manejo comprometem a conservação dos solos (Fig. 4) em áreas com declives em geral, abaixo de 30\%, distribuídas em diferentes situações de relevo, desde as baixas rampas junto à planície fluvial até as superfícies mais elevadas junto aos interflúvios.

Alta (48,5\%): Essa categoria independe da litologia relaciona-se às áreas alteradas pela ação antrópica onde as técnicas de manejo comprometem de modo mais significativona categoria anterior a conservaçáo dos solos em áreas com declives em geral acima de $12 \%$, distribuídas em topos médios e estreitos e ao longo das vertentes.

Muito Alta (6,5 \%): Essa categoria independe da litologia e da morfologia do terreno embora a situação possa ser agravada pelo grau maior de suscetibilidade à desestabilização destes componentes e/ou sensibilidade destes aos agentes externos de morfogênese. 
Fundamentalmente relaciona-se às áreas muito alteradas pela ação antrópica e às áreas com solos expostos e aos corpos de água em geral (3,3\%) stes, em particular, pela constante alteração em sua carga de sedimentos em suspensão e ao risco de contaminação por materiais solúveis.

\section{5 - Conclusóes}

A metodologia utilizada, tendo como base a proposta de Tricart, permitiu, a partir da caracterização geoambiental da Bacia do Rio Verde, identificar a fragilidade potencial e a fragilidade emergente, frente à ação humana, na desestabilização do meio ambiente.

Os resultados mostraram que do ponto de vista da fragilidade potencial da bacia a mesma pode ser considerada, como um todo, de baixa a moderada, contrapondo-se à fragilidade emergente que apresenta alguns índices elevados, considerados críticos. Tal circunstância aponta para a necessidade de açôes coordenadas pelo poder público no que tange ao planejamento e gestáo ambiental da bacia, no sentido de sua estabilidade.

Agradecimentos - Agradecemos, em primeiro lugar, à PETROBRAS que tornou possível esse estudo; aos estagiários do Curso de Geografia da Universidade Federal do Paraná, pelo seu desempenho na confecção dos mapas e ao Eng. Augusto Muratori pela revisão.

\section{Referências Bibliográficas}

AB'SABER, A. N. (1969) - Pedimentos e Bacias Detríticas Pleistocênicas em São Paulo. Geomorfologia, USP, Instituto de Geografia, (9): 1-12.

BECKER, R. D. (1982) - Distribuição dos Sedimentos Cenozóicos na Região Metropolitana de Curitiba e sua relação com a estrutura geológica e morfológica regional. Porto Alegre, 237p. Tese. Doutorado. Universidade Federal do Rio Grande do Sul.

BIGARELLA, J. J. \& SALAMUNI, R. (1959) - Notas complemenares à planta da cidade de Curitiba e arredores. Bol. Do Inst. De Biologia e pesquisas tecnológicas. Curitiba, n. 40 p. 1-14.

BIGARELLA, J. J. et al. (1979) - Recursos Naturais. Ouro Fino. Regiāo Metropolitana de Curitiba. Secretaria de Estado do Planejamento. 30p.

CANALI, N. E. \& MURATORI A. M. (1981) - Síntese da evolução geomorfológica da Bacia Sedimentar de Curitiba. In: Simp. Regional de Geologia, 3, Atas, v.2, p. 335-362.

KLEIN, R. M. \& HATSCHBACH, G. (1962) - Fitofisionomia e notas sobre a vegetação para acompanhar a planta fitogeográfica do Município de Curitiba e arredores (Paraná). Boletim da Universidade do Paraná, Curitiba, n. 4, p. 1-29.

KÖPPEN, W. \& GEIGER, R. (1928) - Klimate der Erde. Gotha: Verlag Justus Perthes. Wall-map 150cmx$200 \mathrm{~cm}$.

MAACK, R. (1968) - Geografia física do Estado do Paraná. 1ª. Ed. Curitiba: Banco de desenvolvimento do Paraná; Universidade Federal do Paraná; Instituto de Biologia e Pesquisas Tecnológicas.

MAACK, R. (1947) - Breves notícias sobre a geologia dos Estados do Paraná e Santa Catarina. Arq. De Biologia e Tecnologia. Curitiba, v.II p. 63-154. 
MURATORI, A. M. \& PASSOS, E. (2011) - Fragilidade potencial e emergente do solo. In: Eutrofização em reservatórios:gestáo preventiva. Estudo interdisciplinar na Bacia do rio Verde, PR / Editores Cynara 1. N. Cunha et al. Curitiba Editora UFPR,127-142.

PASSOS, E. (1987) - Relação entre vertentes e solos em Umbará/Curitiba-PR. Dissertação de Mestrado. Programa de Pós-Graduação em Ciência do Solo da Universidade Federal do Paraná. Orientador Arthur dos Santos Filho. Curitiba.

ROSS, J. L. S. (1987) - Estudo e Cartografia Geomorfológica da Província Serrana - MT - Tese de doutorado apresentada à FFLCH-USP São Paulo-SP.

SALAMUNI, E. (1998) - Tectônica da Bacia Sedimentar de Curitiba (PR). Instituto de Geociências e Ciências Exatas, Universidade Estadual Paulista-Rio Claro. Tese de Doutoramento.

TRICART, J. (1977) - Ecodinâmica. Rio de Janeiro, IBGE, Diretoria Técnica, SUPREN. 